\title{
Analytical Model of Power MOSFET Switching Losses due to Parasitic Components
}

\author{
Edoardo Locorotondo, Luca Pugi \\ Dept. of Industrial Engineering \\ University of Florence \\ Florence, Italy \\ Corresponding author: edoardo.locorotondo@unifi.it
}

\author{
Fabio Corti, Lorenzo Becchi, Francesco Grasso \\ Dept. of Information Engineering \\ University of Florence \\ Florence, Italy
}

\begin{abstract}
In this paper the effect of parasitic elements on the MOSFETs switching transient through a linear and timevarying electrical model is presented. In particular, the effect of non-linear junction capacitances and the stray inductances have been studied and compared in terms of switching loss and waveform overshoot and ringing. The results obtained with the proposed model are validated by comparison between the model implemented in Matlab/Simulink and LTspice simulations. Considerations about the impact of stray inductances and switching energy losses are conducted and some observations to reduce energy losses are proposed.
\end{abstract}

Keywords - Power MOSFET; Switching Losses; Stray Inductance; Junction Capacitance; Parasitic Elements.

\section{INTRODUCTION}

Power density of electronic switching devices is continuously increasing thanks to the introduction of components able to work at higher switching frequency. Thanks to the introduction of wide bandgap (WBG) semiconductor power converters are nowadays able to work at higher voltages, temperatures and frequency than conventional semiconductor material. In particular, the possibility to work at higher operating frequency allows higher power density and therefore save space, material and therefore reduce costs. Thus, if working at higher frequency brings several benefits, more attention must be placed during the design step. Predicting the power MOSFET losses is of primary importance for an optimum thermal design of the heatsink or cooling system, a fundamental aspect in many different high power sector such as automotive, railway and avionics [1]-[6]. Switching power converter are commonly based on PWM DC-DC converters which are simple, require a low number of components, and are widely investigated [7][11]. However the operations of these circuits is largely affected by parasitic components introduced by actual devices utilized in assembly the converter circuits [14]-[19]. When these parameters are takin into account the analysis of the circuit become cumbersome and require computer aided techniques [20]-[27]. In literature several studies were made to estimate the power losses with different degrees of approximation. In [19], a simple method to get a first and fast estimation of power losses is shown. This approach can be useful to get a rough estimation, but it does not consider the parasitic components.

This work is part of the OBELICS project which has received funding from the European Union Horizon 2020 research and innovation program under grant agreement No. 769506
In [28] the impact of nonlinear junction capacitance on switching transient and its modeling for Silicon Carbide (SiC) MOSFET is shown. Experiments show that without full consideration of nonlinear junction capacitances, some significant deviations between simulated and measured results will emerge in the switching waveforms.

In [29] a detailed study of SiC MOSFET switching characteristics is shown. The switching performance of $\mathrm{SiC}$ MOSFETs are evaluated, in terms of turn on and turn off voltage and current in relation to gate driver maximum current, gate resistance, common source inductance and parasitic switching loop inductance. In [30][31] useful parameter extraction sequence of a $\mathrm{SiC}$ MOSFET is presented. The procedure makes possible to find several characteristics parameters starting from electrical tests and datasheets information. In [32] a circuit-level analytical model is shown. In particular, this model takes MOSFET parasitic capacitances and inductances, circuit stray inductances, and reverse current of the freewheeling diode into consideration is given to evaluate the MOSFET switching characteristics.

In this paper, starting from the information in [6]-[33] a state-space linear and time varying MOSFET model able to consider the non-linear junction capacitance and the stray inductance is proposed. This model is implemented in Matlab/Simulink. The results obtained are validated on LTspice using an accurate model of SiC MOSFET provided from the manufacturer. Since junction capacitances are characteristic of the MOSFET more attention is focused to the effect of the stray inductances and how they interact with the capacitances. The results show how each inductance affect the turn-on and turn off transient in terms overshoot, ringing and power losses. Some designing good practice observation to reduce the stray inductance are proposed.

\section{MOSFETS SWITCHING TRASIENT DESCRIPTION}

Fig. 1 shows the current, voltage and power waveforms during turn-on and turn off transient of a power MOSFET as derived in [32] where a linear time-variant model of the device has been introduced to estimate the power losses starting from the characteristics reported in the datasheet. Both turn-on and turn-off can be divided in four main stages by considering the drain-to-source current $I_{D S}$, the drain-to-source voltage $V_{D S}$, the gate-to-source voltage $V_{G S}$ and the gate current $I_{G}$. These 
waveforms are useful to estimate the power losses due to both conduction and switching.

Starting from [32], non-linear models of the parasitic capacitances of the MOSFET have been included in the switching model.

\section{ANALYTICAL Model of the SWITCHING TRANSIENT}

Every stage can be modelled by a state-space representation. Being a time-variant model, some continuity conditions are necessary when a transition from a stage to another one occurs.

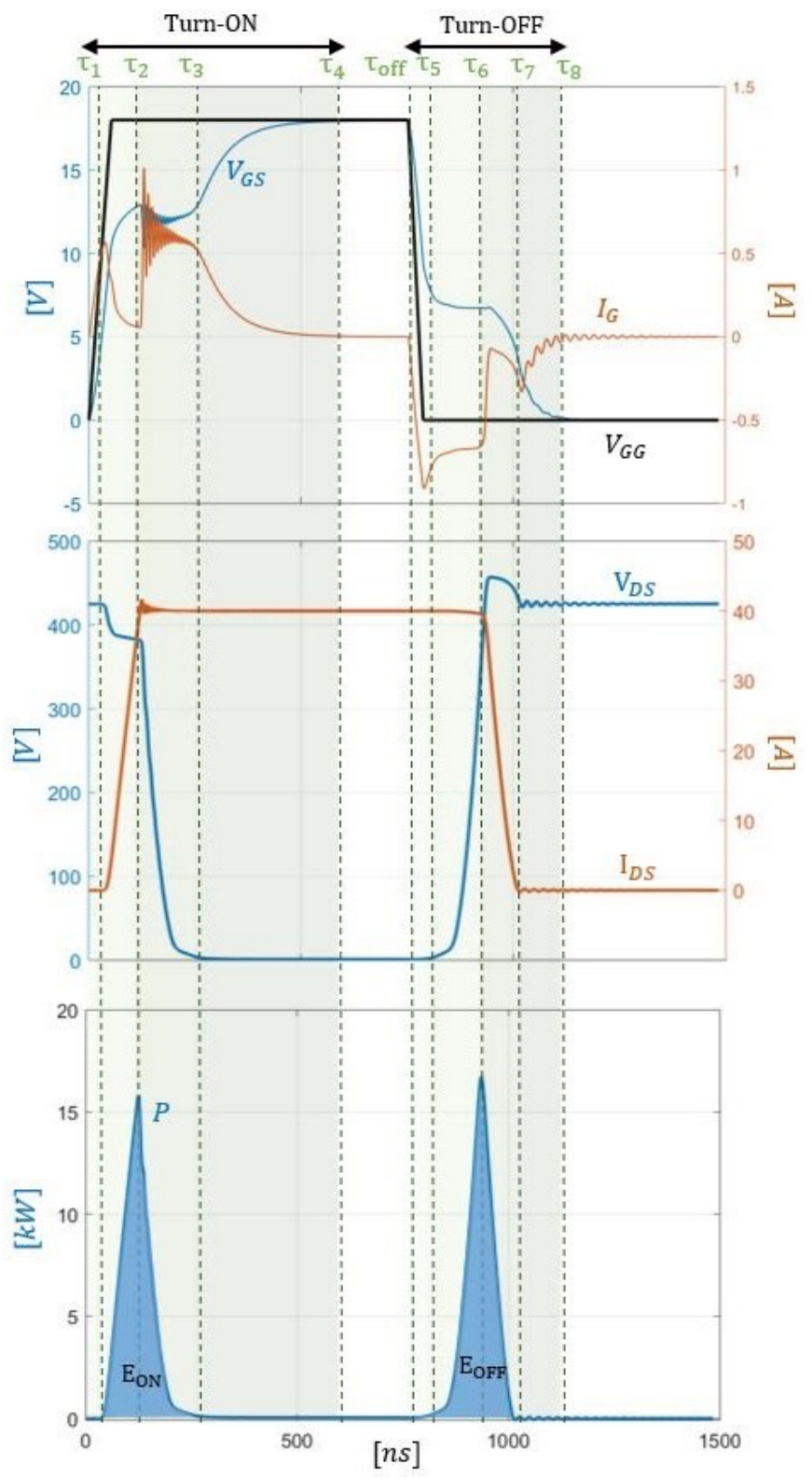

Fig. 1 Stages during turn-on and turn-off switching transient.

The general representation of the $i$-stage can be written as the following time-discrete Linear Time-Varying (LTV) dynamic system.

$$
x_{k+1}=A_{i} k_{k}+B_{i} u_{k}
$$

Where $x_{k}$ and $u_{k}$ are respectively the state and the input of the dynamic system at the instant time $k T$, for the integer index $k$ $\in \mathbb{N}$ and the sample time $T$. The state matrix is $A_{i}$ and the input-to-state matrix is $B_{i}$.
The State variable used in this paper is a five element vector $x=\left[V_{G S}, V_{D S}, V_{A K}, I_{D S}, I_{G}\right]$ where $V_{G S}$ is the internal gateto-source voltage, $V_{D S}$ is the internal drain-to-source voltage, $V_{A K}$ is the voltage of a diode placed between the drain and the main alimentation, $I_{D S}$ is the drain-to-source current and $I_{G}$ is the gate current. The input variable is $u=\left[V_{T H}, V_{T H, l}, V_{D D}, I_{D D}\right.$, $V_{G G}$ ], where $V_{T H} V_{T H, l}$ are the MOSFET threshold voltage [32], $V_{D D}$ is the voltage supply, $I_{D D}$ is the steady output current and $V_{G G}$ is the driver voltage.

\section{IMPROVED CDS AND CGD NON-LINEAR MODEL}

The proposed model is time-varying since the parasitic capacitances are dependent from the applied voltage. These dependences can be found from the MOSFET datasheet and it is shown in Fig. 2. From the input capacitance $C_{I S S}$, the output capacitance $C_{O S S}$ and the reverse transfer capacitance $C_{R S S}$ can be found the gate-to-drain capacitance $C_{G D}=C_{R S S}$, the drain-tosource capacitance $C_{D S}=C_{O S S}-C_{R S S}$ and the gate-to-source capacitance $C_{G S}=C_{I S S}-C_{R S S}$. In [28] are modelled the effect of the non-linear capacitances on the transient characteristics of the switching process. The effect of the nonlinearity of $C_{G S}$ can be neglected, therefore it is assumed constant [32]. On the other hand, if $C_{D S}$ is assumed simply constant, there will be a serious deviation between the simulation and experimental results in switching transient. The factor that made the $C_{D S}$ changes are substantially two: the drain-to-source voltage $V_{D S}$ and the gate-to-drain voltage $V_{G D}$. In fact, as a junction capacitance, $C_{D S}$ decreases significantly with the increase of $V_{D S}$ since the depletion width changes with bias voltage. However, when MOSFET is turned ON or in the switching transient, $C_{D S}$ will be impacted by the conductive channel and the non-uniform distribution of electrons caused by the gateto-drain voltage $V_{G D}$, which is the second factor mentioned above. As shown in [28], the $C_{D S}$ can be view as a linear combination of two parameters, $C_{D S, v d s}$, a hyperbolic function of $V_{D S}$, and $\delta$, which is a function of $V_{G S}$.

$$
C_{D S}=C_{D S, v d s} \cdot \delta_{d s}
$$

where

$$
C_{D S, v d s}=\frac{C_{O}}{\sqrt{1+\frac{V_{D S}}{V_{b i}}}}
$$

and

$$
\delta_{d s}=\left\{\begin{array}{cc}
1 & V_{G S}<V_{T H} \\
\left(1-\delta_{d s 0}\right) e^{-\alpha\left(V_{T H}-V_{G S}\right)}+\delta_{d s 0} & V_{G S}>V_{T H}
\end{array}\right.
$$

While $\delta_{\mathrm{ds} 0}$ can be approximately regarded as the attenuation ratio of $C D S$ on the condition that MOSFET is fully turned- ON, $\alpha$ is an adjustable parameter. Unfortunately, the actual value of $C D S$ in ON-state is difficult to measure as it is almost bypassed by the ON-state resistance. Thus, the two undetermined parameters $\delta d s 0$ and $\alpha$, probably only can be obtained by finite-element analysis or experience at present.

Regarding the gate-to-drain modelling, its non-linearity is faced up in [30] where, in transient equations section of table 1 , the value of the capacity is related directly to the drain-gate voltage. 


$$
C_{G D}=\left\{\begin{array}{cc}
C_{o x d} & V_{D S}<V_{G S}-V_{T d} \\
\frac{C_{o x d} \cdot C_{g d j}}{C_{o x d}+C_{g d j}} & V_{D S}>V_{G S}-V_{T d}
\end{array}\right.
$$

Where $C_{\text {oxd }}$ is the Gate-drain overlap oxide capacitance and $C_{g d j}$ is the gate-drain depletion capacitance and $V_{T d}$ is the gate-drain overlap depletion threshold.

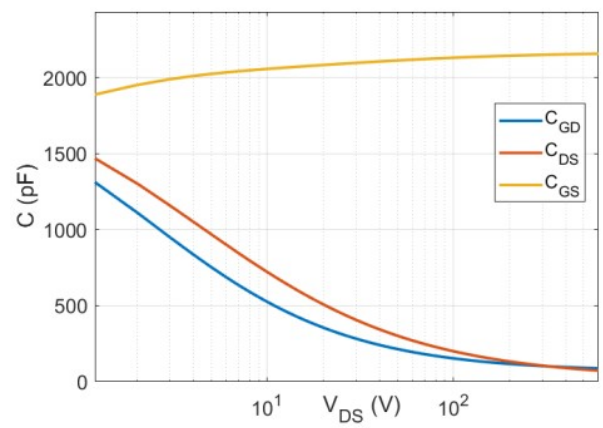

(a)

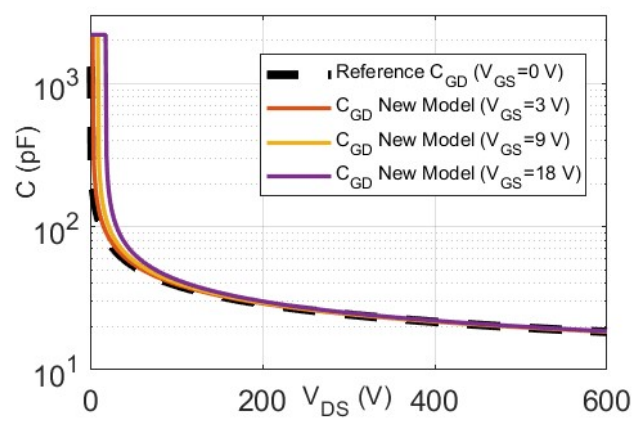

(b)

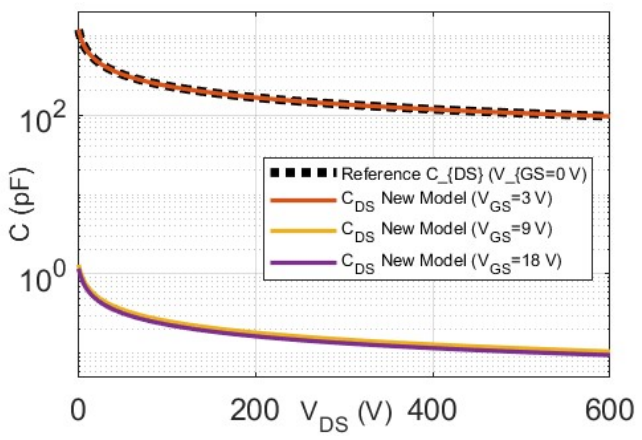

(c)

Fig. 2 Non-linear capacitances (a) Non-linear capacitances varying drain-to source voltage. Gate-to-drain capacitance $\mathrm{C}_{\mathrm{GD}}$, the drain-to-source capacitance $\mathrm{C}_{\mathrm{DS}}$ and the gate-to-source. (b) Dependence of $\mathrm{C}_{\mathrm{GD}}$ from gate to source voltage. (c) Difference between classical model presented in [2] and the new proposed model dependent from the Gate-to-Source voltage.

The $C_{g d j}$ can be expressed as:

$$
C_{g d j}=\frac{A_{g d} \cdot \varepsilon_{s e m i}}{W_{g d j}}
$$

where $A_{g d}$ is the Gate-drain overlap area, $\varepsilon_{\text {semi }}$ is the semiconductor dielectric constant and $W_{g d j}$ is the gate to drain depletion width body junction and can be calculates as

$$
W_{g d j}=\sqrt{\frac{2 \varepsilon_{\text {semi }}\left(V_{d s}+V_{T d}\right)}{q N_{b}}}
$$

With $q$ fundamental electronic charge and $N_{b}$ base dopant density.

\section{MOdEL VALIDATION}

The analytical model of Power MOSFET mentioned in Section II-III-IV was implemented in Matlab-Simulink software. To validate the results obtained with the analytical model, several simulations were performed on LTspice. The chosen component is the $\mathrm{SiC}$ power MOSFET SCT3022AL since the manufacturer provide an accurate LTspice Model. This MOSFET has a conduction resistance $r_{D S}=22 \mathrm{~m} \Omega$, a drain-source breakdown voltage $V_{D S S}=650 \mathrm{~V}$ and a continuous drain current $I_{D D}=93 \mathrm{~A}$. The MOSFET behaviour is analysed in a typical double pulse test system as shown in Fig. 3. Compared to the circuit presented in [32], the body diode of an SCT3022AL is used instead of a Schottky diode (C4D10120D). When the component is connected to the PCB, some parasitic inductances are created at the electric terminations. In this paper, it is assumed as nominal value $L_{S}=9 \mathrm{nH}, L_{D}=5 \mathrm{nH}$ and $L_{G}=15 \mathrm{nH}$. The comparison between the analytical model assuming $V_{D D}=420 \mathrm{~V}$ and $I_{D D}=40 \mathrm{~A}$ and the LTspice simulations are shown in Fig. 4. It's noticeable that the analytical model implemented in Matlab/Simulink is validated by the comparison between output MOSFET current, voltage and power delivered.

\section{PARASITIC INDUCTANCES EFFECT ON MOSFET TRANSIENT}

After validating the model, a study on how the parasitic inductances affect the turn-on and turn-off transient is carried out. In the following analysis a single inductance is changed maintaining constant the other two to the nominal values.

\section{A. Effect of the Parasitic Gate Inductance $L_{G}$}

The waveforms for three values of gate inductance $L_{G}$ are shown in Fig. 5, while the energy dissipated during a turn-ON and turn-OFF transient are summarized in Table I. This inductance tends to resonate with the MOSFET input capacitance, causing oscillations in the gate-to-source voltage $V_{G S}$.

TABLE I. SWITCHING ENERGY DISSIPATION FOR DIFFERENT GATE INDUCTANCE

\begin{tabular}{|c|c|c|c|}
\hline Switching Energy & $\boldsymbol{L}_{\boldsymbol{G}}=\mathbf{1 5} \mathbf{n H}$ & $\boldsymbol{L}_{\boldsymbol{G}}=\mathbf{1 5 0} \mathbf{n H}$ & $\boldsymbol{L}_{\boldsymbol{G}}=\mathbf{5 0 0} \mathbf{n H}$ \\
\hline \hline Turn-ON & $149 \mu \mathrm{J}$ & $176 \mu \mathrm{J}$ & $159 \mu \mathrm{J}$ \\
Turn-OFF & $145 \mu \mathrm{J}$ & $98 \mu \mathrm{J}$ & $87 \mu \mathrm{J}$ \\
\hline
\end{tabular}

For this reason, it is recommended to minimize $L_{G}$ placing the gate driver as close as possible to the power device, ensuring the correct gating of the device and avoiding its spurious operation leading to undesirable faults. Apart from this recommendation, the influence of $L_{G}$ on the $V_{D S}$ and $I_{D S}$ is limited if compared to the effect of the other two inductances. 


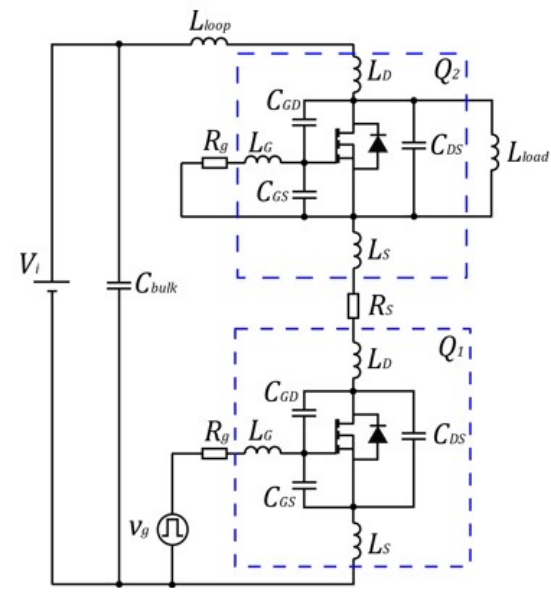

Fig. 3. Test circuit used to estimate the power losses.

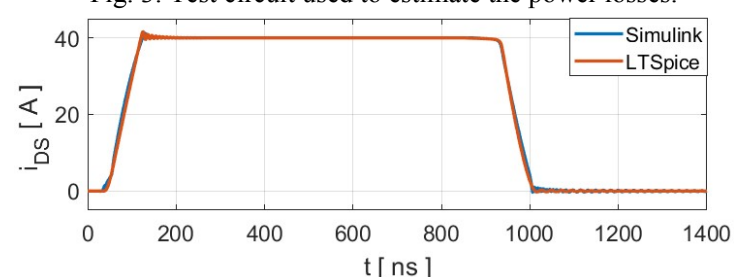

(a)

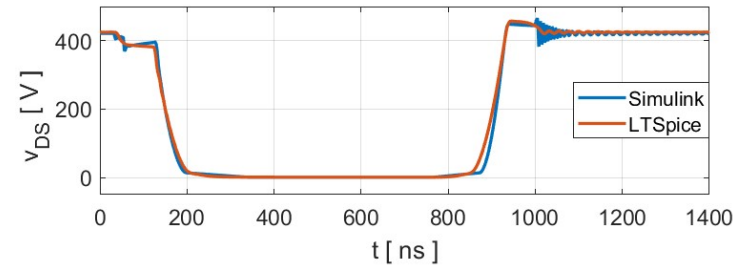

(b)

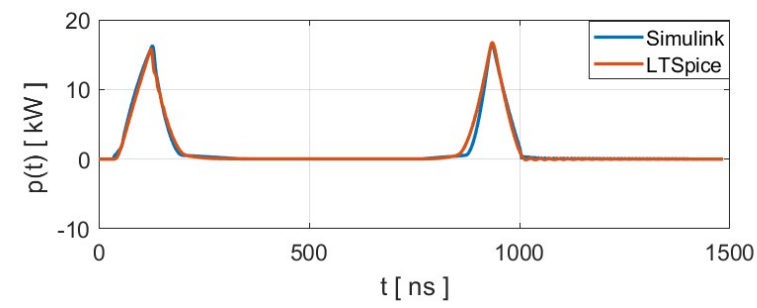

(c)

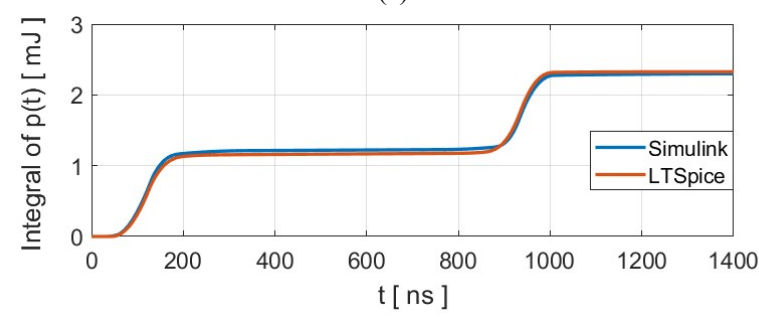

(d)

Fig. 4. Comparison between analytical model and LTspice simulations. (a) Drain-to-Source current $I_{D S}$. (b) Drain-to-Source voltage $V_{D S}$. (c) Istant power losses dissipation $p$. (d) Energy losses during the switching.

\section{B. Effect of the Parasitic Drain Inductance $L_{D}$}

The drain capacitance $L_{D}$, also called in literature switching loop capacitance, resonates with the MOSFET output capacitance and the diode junction capacitance during the switching transient. The oscillation produced are then coupled into the gate loop through the gate-to-drain capacitance $C_{G D}$. Thus, increasing $L_{D}$, ringing are introduced in $V_{G S}, V_{D S}$, and $I_{D S}$, as shown in Fig. 6.
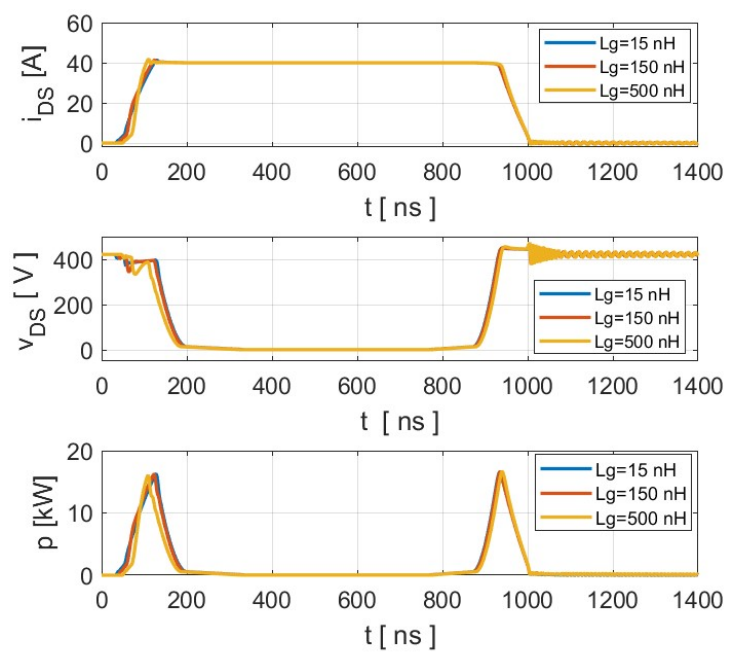

Fig. 5. Effect of gate inductance $L_{G}$. (top) Drain to source current $I_{D S}$. (middle) Drain to source voltage $V_{D S}$. (bottom) Istant Power $p$.

TABLE II. SWITCHING ENERGY DISSIPATION FOR DIFFERENT DRAIN INDUCTANCE

\begin{tabular}{|c|c|c|c|}
\hline \multicolumn{4}{|c|}{ INDUCTANCE } \\
\hline \multirow{2}{*}{ Switching Energy } & $\boldsymbol{L}_{\boldsymbol{D}}=\mathbf{5} \mathbf{n H}$ & $\boldsymbol{L}_{\boldsymbol{D}}=\mathbf{5 0} \mathbf{n H}$ & $\boldsymbol{L}_{\boldsymbol{D}}=\mathbf{1 0 0} \mathbf{n H}$ \\
\hline \hline Turn-ON & $151 \mu \mathrm{J}$ & $133 \mu \mathrm{J}$ & $115 \mu \mathrm{J}$ \\
Turn-OFF & $141 \mu \mathrm{J}$ & $154 \mu \mathrm{J}$ & $166 \mu \mathrm{J}$ \\
\hline
\end{tabular}
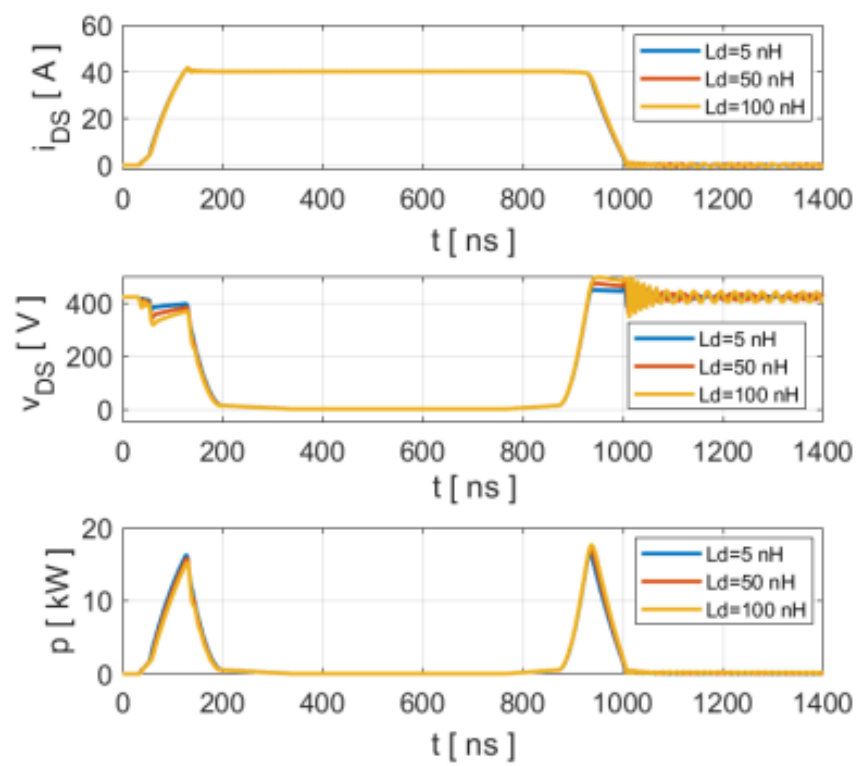

Fig. 6. Effect of gate inductance $L_{D}$. (top) Drain to source current $I_{D S}$. (middle) Drain to source voltage $V_{D S}$. (bottom) Istant Power $p$.

This inductance affects the switching transient more significantly than the gate inductance, causing even worse oscillations and stresses on the device. The voltage overshoot of $V_{D S}$ increase by increasing $L_{D}$. For this reason, is recommended to reduce the drain loop inductance to ensure the safety of the MOSFET. Moreover, another effect of $L_{D}$ is the current slew rate reduction leading to higher switching losses. The energy dissipated during a turn-ON and turn-OFF transient are summarized in Table II, varying $L_{D}$.

\section{Effect of the Parasitic Source Inductance LS}

The source inductance $L_{S}$ creates a negative feedback from the switching loop to the gate loop. When the drain 
current $I_{D S}$ changes during the switching, the voltage across $L_{S}$ counteracts the change of the gate voltage slowing down slew rate of the current $I_{D S}$. This behavior can be seen in Fig. 7 (a). On the other hand, these inductance does not affect the slew rate of the voltage $V_{D S}$. In addition, increasing $L_{S}$, the ringing across $V_{D S}$ are reduced but higher switching losses occurs due to slew rate reduction. The energy dissipated during a turn-ON and turn-OFF transient are summarized in Table III, varying $L_{S}$.

TABLE III. SWITCHING ENERGY DISSIPATION FOR DIFFERENT SOURCE INDUCTANCE

\begin{tabular}{|c|c|c|c|}
\hline Switching Energy & $\boldsymbol{L}_{\boldsymbol{S}}=\mathbf{3 . 5} \mathbf{n H}$ & $\boldsymbol{L}_{\boldsymbol{S}}=\mathbf{9} \mathbf{n H}$ & $\boldsymbol{L}_{\boldsymbol{S}}=\mathbf{1 8} \mathbf{n H}$ \\
\hline \hline Turn-ON & $102 \mu \mathrm{J}$ & $151 \mu \mathrm{J}$ & $241 \mu \mathrm{J}$ \\
Turn-OFF & $110 \mu \mathrm{J}$ & $142 \mu \mathrm{J}$ & $217 \mu \mathrm{J}$ \\
\hline
\end{tabular}
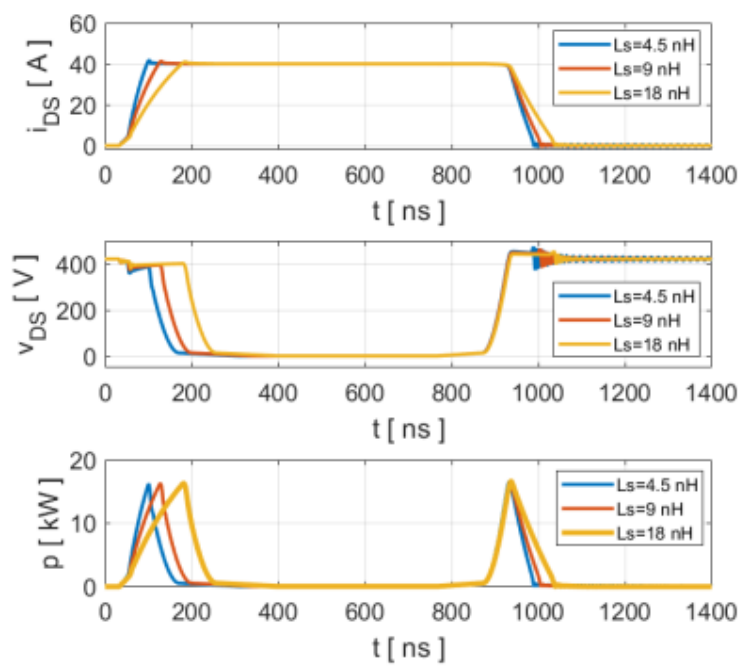

Fig. 7. Effect of gate inductance $L_{S}$. (top) Drain to source current $I_{D S}$. (middle) Drain to source voltage $V_{D S}$. (bottom) Istant Power $p$.

\section{COMPARISON AND SUMMARY}

To have a complete overview of the stray inductances effects in SiC MOSFET, the energy losses in turn-ON and turn-OFF phases are calculated separately, varying the inductances $L_{G}, L_{D}, L_{S}$. The range of the stray inductances is appropriately assessed, referring to [31] and Table I, II, III. Fig. 8 shows that in both the transient phases, the variation of the gate stray inductance $L_{G}$ contributes very few to the switching losses of the Sic MOSFET, while, the variation of the source stray inductance $L_{S}$ highly affects the switching losses, especially for the turn-ON phase, as shown also in the Fig. 7. Despite the energy losses values during the turn-OFF is $[1.0-1.4] \mu \mathrm{J}$, while during the turn-ON higher $[0.4-1.5]$ $\mu \mathrm{J}$. Therefore, it is important in the design to take care of on the connection of the source pin.
Turn on
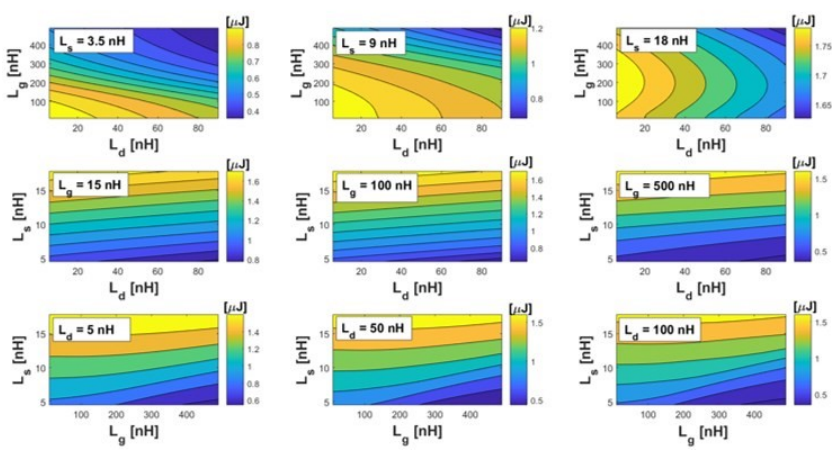

(a)

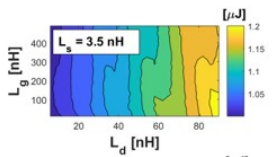

Turn off
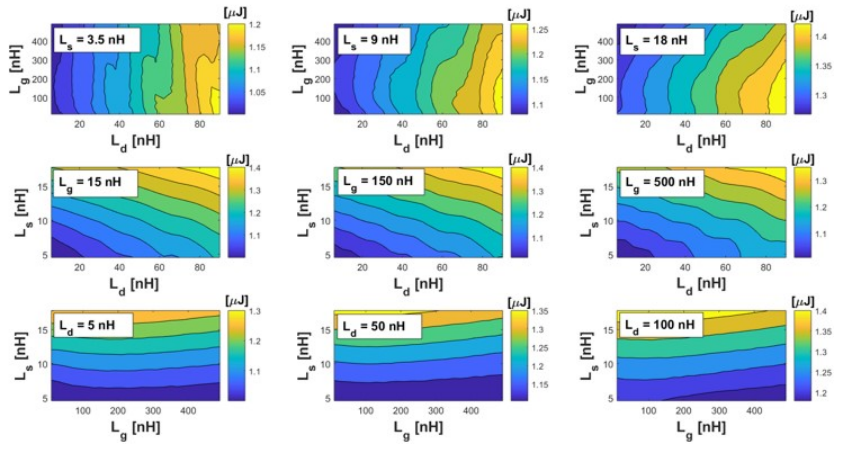

(b)

Fig. 8. Energy dissipated in analytical model of Sic MOSFET during the single Turn-ON transient (a) and Turn-OFF (b) transient, depending on stray inductance $L_{S}, L_{G}, L_{D}$.

\section{CONCLUSIONS}

The effect of stray inductances has been analytically analyzed considering the MOSFET non-linear junction capacitance. The results obtained are in good agreement with the LTspice model provided from the manufacturer. The results show that the source capacitance $L_{S}$ affect the switching transient more than the others inductances: even small values produce significant negative effects. For this reason, during the design phase, the source connection is crucial to reduce the switching losses. On the other hand, the drain inductance $L_{D}$ affect less than the waveforms, but it is the first responsible of the overshoot on $V_{D S}$. Therefore $L_{S}$, must be kept low to avoid that $V_{D S}$ let reach values higher that the breakdown voltage. Finally, the gate voltage $L_{G}$ affect less than all the turn-on and turn-off transient, but it is recommended to maintain low value to ensure the correct gating of the device and avoid its spurious operation leading to undesirable faults.

As future works the model will be improved coupling this electrical model with a thermal model. Indeed, in real applications, all the parameters of the model are temperature dependent. The coupling of an electric model and a thermal model can be useful to better understand the system performance and know the junction temperature of each switching device.

\section{REFERENCES}

[1] L. Pugi, A. Reatti, F. Corti, “Application of Wireless Power Transfer to Railway Parking Functionality: Preliminary Design Considerations with Series-Series and LCC Topologies", (2018) Journal of Advanced Transportation, 2018, art. no. 8103140 . 
[2] Pugi, L., Grasso, F., Pratesi, M., Cipriani, M., Bartolomei, A. Design and preliminary performance evaluation of a four wheeled vehicle with degraded adhesion conditions (2017) International Journal of Electric and Hybrid Vehicles, 9 (1), pp. 1-32.

[3] Pugi, L., Grasso, F., Rossi, G. Energy Simulation of Tramway Systems, Simplified and Efficient Models (2018) Proceedings - 2018 IEEE International Conference on Environment and Electrical Engineering and 2018 IEEE Industrial and Commercial Power Systems Europe, EEEIC/I and CPS Europe 2018, DOI: 10.1109/EEEIC.2018.8494431

[4] Grasso, F., Allotta, B., Rindi, A., Pugi, L., Fusi, A., Ussi, A. Transient power pulse calculation in electric motor driving reciprocating compressor (2016) EEEIC 2016 - International Conference on Environment and Electrical Engineering, art. no. 7555692,

[5] Pugi, L., Allotta, B., Cipriani, M., Pratesi, M., Bartolomei, A., Grasso, F. Integrated design and simulation of a direct drive, electric shuttle vehicle(2016) The Dynamics of Vehicles on Roads and Tracks Proceedings of the 24th Symposium of the International Association for Vehicle System Dynamics, IAVSD 2015, pp. 679-690

[6] F. Corti, A. Reatti, M. Pierini, R. Barbieri, L. Berzi, A. Nepote, P. De La Pierre, "A Low Cost Secondary Side Votrolled Electric Vehicle Wireless Charging System using a Full-Active Rectifier", International Conference of Electrical and Electronic Technologies for Automotive, 9-11 July 2018, Milan, Italy.

[7] A. Reatti, M. Balzani, "PWM switch model of a buck-boost converter operated under discontinuous conduction mode," Proceedings of IEEE Circuits and Systems, 2005. 48th Midwest Symposium on Circuits and Systems, Cincinnati, OH, USA, August 7-10, 2005 Page(s): 667-670.

[8] A. Ayachit, A. Reatti, M. Kazimierczuk, "Small-Signal Model of the Boost PWM DC-DC Converter at Boundary-Conduction Mode Using Circuit Averaging Technique", Proceedings of 2015 IEEE International Symposium on Circuits and Systems, Lisbon, Portugal, May 24-27, 2015, pp. 229-232.

[9] D. Saini, A. Reatti, M. K. Kazimierczuk, "Average Current-Mode Control of Buck DC-DC Converter with Reduced Control Voltage Ripple", Proc. of 42nd Annual Conference of IEEE Industrial Electronics Society, October 24-27, 2016, Florence, Italy, pp. 3270 3275.

[10] A. Ayachit, A. Reatti, M. K. Kazimierczuk, "Small-Signal Modeling of PWM Dual-SEPIC DC-DC Converter by Circuit Averaging Technique", Proc. of 42nd Annual Conference of IEEE Industrial Electronics Society, October 24-27, 2016, Florence, Italy, pp. 36063611 .

[11] H. Al-Baidhani; M. K. Kazimierczuk; A. Reatti, "Nonlinear Modeling and Voltage-Mode Control of DC-DC Boost Converter for CCM", 2018 IEEE International Symposium on Circuits and Systems (ISCAS), May 27-30, 2018, Florence, Italy, pp. 1-5.

[12] D. K. Saini; A. Chadha; A. Ayachit; A. Reatti; M. K. Kazimierczuk, "Duty Cycle and Input-to-Output Voltage Transfer Functions of Tapped-Inductor Buck DC-DC Converter", 2018 IEEE International Symposium on Circuits and Systems (ISCAS), May 27-30, 2018, Florence, Italy, pp. 1-5.

[13] H. Al-Baidhani, M. K. Kazimierczuk, T. Salvatierra, A. Reatti, F. Corti, "Sliding-Mode Voltage Control of Dynamic Power Supply for CCM", 2019 IEEE International Symposium on Circuits and Systems (ISCAS), May 26-29, 2019, Sapporo, Japan pp. 1-5.

[14] A. Luchetta, S. Manetti, M. C. Piccirilli, A. Reatti and M. K. Kazimierczuk, "Comparison of DCM operated PWM DC-DC converter modelling methods including the effects of parasitic components on duty ratio constraint", Proceedings of IEEE 15th International Conference on Environment and Electrical Engineering, Rome, Italy, June 10th-13th 2015, pp. 766-771.

[15] A. Luchetta, S. Manetti, M. C. Piccirilli, A. Reatti and M. K. Kazimierczuk, "Effects of Parasitic Components on Diode Duty Cycle and Small-Signal Model of PWM DC-DC Buck Converter in DCM", Proceedings of IEEE 15th International Conference on Environment and Electrical Engineering, Rome, Italy, June 10th-13th 2015, pp. 772777.

[16] A. Luchetta, S. Manetti, M. C. Piccirilli, A. Reatti and M. K. Kazimierczuk, "Derivation of Network Functions for PWM DC-DC Buck Converter in DCM Including Effects of Parasitic Components on Diode Duty-Cycle", Proceedings of IEEE 15th International Conference on Environment and Electrical Engineering, Rome, Italy, June 10th-13th 2015, pp. 778-783.

[17] A. Reatti, F. Corti, A. Tesi, A. Torlai, M. K. Kazimierczuk, "Nonlinear Exact Analysis and Solution of Power Stage of DC-DC PWM Boost
Converter", 2019 IEEE International Symposium on Circuits and Systems (ISCAS), May 26-29, 2019, Sapporo, Japan, pp. 1-5.

[18] A. Reatti, F. Corti, A. Tesi, A. Torlai, M. K. Kazimierczuk, "Effect of Parasitic Components on Dynamic Performance of Power Stages of DC-DC PWM Buck and Boost Converters in CCM", 2019 IEEE International Symposium on Circuits and Systems (ISCAS), May 2629, 2019, Sapporo, Japan pp. 1-5.

[19] E. Locorotondo, A. Reatti, F. Corti, L. Pugi, L. Becchi "Analytical Model of Power MOSFET Switching Losses due to Parasitic Components", 2019 IEEE 5th International Forum on Research and Technology for Society and Industry (RTSI), September 9-12, 2019, Palermo, Italy, pp. 1-6.

[20] F. Grasso, S. Manetti, M. C. Piccirilli, A. Reatti, F. Corti, M. Catelani, L. Ciani, M. K. Kazimierczuk, "A Laplace transform approach to the simulation of DC-DC converters", International Journal of Numerical Modelling: Electronic Networks, Devices and Fields, Volume 6, No. 2, Pages 1-17, May. 2019.

[21] F. Grasso, A. Luchetta, S. Manetti, M. C. Piccirilli, A. Reatti "Symbolic analysis techniques for fault diagnosis and automatic design of analog circuits". In: M. Fakhfakh, E. Tlelo-Coutle, F. U. Fernandez. Design of analog circuits through symbolic analysis. p. 361-398, Bentham Science Publishers, ISBN: 9781608050956, doi: 10.2174/97816080509561120101, 2012.

[22] F. Grasso, A. Luchetta, S. Manetti, M. C. Piccirilli, A. Reatti "SapWin 4.0 - A New Simulation Program for Electrical Engineering Education Using Symbolic Analysis". Wiley Computer Applications in Engineering Education, Vol. 4, No. 1, pp. 44-57, January 2016.

[23] G. Fontana, F. Grasso, S. Manetti, M. C. Piccirilli, A. Reatti, "A symbolic program for parameter identifiability analysis in systems modeled via equivalent linear time-invariant electrical circuits, with application to electromagnetic harvesters", International Journal of Numerical Modelling: Electronic Networks, Devices and Fields, Volume 30, No. 3, Pages 1-13, June 2017.

[24] A. Reatti, M. Balzani, "Computer aided small-signal analysis for PWM DC-DC converters operated in discontinuous conduction mode," Proceedings of IEEE Circuits and Systems, 2005 48th Midwest Symposium on Circuits and Systems, Cincinnati, OH, USA, August 7-10, 2005 Page(s): 1561 - 1564.

[25] F. Grasso, A. Luchetta, A. Reatti, L. Serri, "Symbolic Analysis of PWM DC-DC Converters operated under both Continuous and Discontinuous Conduction Modes". In: Ninth Int. Workshop on Symbolic and Numerical Methods, Modelling and Applications to Circuit Design (SM2ACD’08). Erfurt, Germany, Oct. 2008, p. 95-101.

[26] F. Grasso, A. Luchetta, S. Manetti, M. C. Piccirilli, A. Reatti, "SapWin 4.0 - An Enhanced Tool for Analysis and Design of Analog Circuits". Proceeding of International Symposium on Fundamentals on Electrical Engineering, Bucharest, Romania, November 28-29, 2014, pp. 1-5.

[27] G.Fontana, F. Grasso, A. Luchetta, S. Manetti, M. C. Piccirilli, A.Reatti, "A new simulation program for analog circuits using symbolic analysis techniques," Proceedings of International Conference on Synthesis, Modeling, Analysis and Simulation Methods and Applications to Circuit Design, SMACD 2015; Istanbul; Turkey; 79 September 2015, pp. 1-4.

[28] K. Chen, Z. Zhao, L. Yuan, T. Lu, F. He "'The Impact of Nonlinear Junction Capacitance on Switching Transient and Its Modeling for SiC MOSFET", IEEE Transactions on Electron Devices, Volume: 62 , Issue: 2 , Feb. 2015 , pp. 333 - 338 .

[29] H. Li, S. Nielsen, "Detail Study of SiC MOSFET Switching Characteristics", IEEE 5th International Symposium on Power Electronics for Distribuited Generation, 24-27 June 2014, Galway, Ireland.

[30] Ty R. McNutt ; Allen R. Hefner ; H. Alan Mantooth ; David Berning ; Sei-Hyung Ryu, "Silicon Carbide Power MOSFET Model and Parameter Extraction Sequence", IEEE Transactions on Power Electronics, Volume: 22 , Issue: 2 , March 2007.

[31] J. Wang, H. Chung, R. Li, "Characterization and Experimental Assessment of the Effects of Parasitic Elements on the MOSFET Switching Performance", IEEE Transaction on Power Electronics, Vol.28, N0.1, pp. 573-590, January 2013.

[32] Y. Wu, H. Li, C. Li, C. Bi, Y. Zhi, W. Yao, G. Liu, "Analytical Modeling of SiC MOSFET during Switching Transient", IEEE International Symposium on Electromagnetic Compatibility, 14-18 May 2018, Singapore.

[33] L. Zhang, S. Guo, X. Li, Y. Lei, W. Yu, A. Huang, "Integrated SiC MOSFET module with ultra low parasitic inductance for noise free ultra high speed switching", IEEE 3rd Workshop on Wide Bandgap Power Devices and Applications, 2-4 Nov. 2015, Blacksburg, USA. 